\title{
GÊNEROS TEXTUAIS EM PROPOSTAS DE PRODUÇÃO ESCRITA EM PROVAS DO EXAME CELPE-BRAS
}

\section{TEXTUAL GENRES IN WRITTEN PRODUCTION PROPOSALS IN CELPE- BRAS EXAM PROOF}

\author{
Jefferson Alves da Rocha ${ }^{1}$ \\ Judithe Genuíno Henrique ${ }^{2}$ \\ Matheus de Almeida Barbosa ${ }^{3}$
}

\section{RESUMO}

Este artigo consiste em analisar propostas de produção de texto com base nas teorias dos gêneros textuais. Para tratar do assunto, realiza-se o levantamento de algumas questões teóricas relacionadas ao trabalho com textos nas aulas de língua portuguesa. Há, dessa forma, o desenvolvimento da abordagem da língua que contempla os aspectos dos gêneros textuais. Há, ainda, algumas questões a respeito do mesmo trabalho realizado nas aulas de PLE. Para análise do presente artigo, observam-se as propostas de produção de texto das três últimas edições do Exame Celpe-Bras, mais especificamente, a terceira e a quarta tarefa das provas. Essa análise procurou investigar se tais propostas seguiam de fato a abordagem de um determinado gênero textual, corroborando com o processo de ensino-aprendizagem nas aulas de PLE.

\section{Palavras-Chave}

Gêneros textuais. Ensino de PLE. Produção de texto. Exame Celpe-Bras.

\begin{abstract}
This article is to analyze text production proposals based on textual genre theories. To address the subject, it is conducted a survey of some theoretical issues related to working with textual genres in Portuguese language classes. Thus, there is the development of the language approach that includes aspects of textual genres. There are also some questions about the same work done in PLE classes. For the analysis of this article, the text production proposals of the last three editions of the Celpe-Bras Exam are observed, more specifically, the third and fourth tasks of the tests. This analysis sought to investigate whether such proposals actually followed the approach of a particular text genre, corroborating the teaching-learning process in PLE classes.
\end{abstract}

\section{KEYWORDS}

Textual genres. PLE teaching. Text production. Celpe-Bras exam.

1 Doutorando em Linguística pela Universidade Federal da Paraíba.

2 Doutoranda em Linguística pela Universidade Federal da Paraíba.

3 Doutorando em Linguística pela Universidade Federal da Paraíba. 


\section{INTRODUÇÃo}

Inicialmente, pode-se mencionar que, nas aulas de língua portuguesa, é fundamental o planejamento de atividades que contemplem os gêneros textuais. Os gêneros textuais podem ser descritos como textos que possuem aspectos comuns com fins comunicativos que permeiam a sociedade. Esses gêneros podem ser orais ou escritos. Pode-se reconhecer um determinado texto como pertencente a tal gênero a partir da maneira que é construído, da sua composição, do estilo, da linguagem, da estrutura, além de outros aspectos que podem ser observados.

Observa-se que as atividades com gêneros textuais nas aulas de português como língua materna podem ser executadas também nas aulas de português como língua estrangeira (doravante, PLE). O trabalho a partir dos gêneros textuais nas aulas de PLE permite o entendimento de aspectos da língua portuguesa, como leitura, oralidade, análise linguística e produção textual.

Para o desenvolvimento deste trabalho, discutiremos questões relacionadas aos gêneros textuais. Mostraremos algumas das teorias e das ideias presentes em trabalhos e em pesquisas na área. Posteriormente, realizaremos algumas considerações a respeito do ensino dos gêneros textuais voltado para aulas de PLE. Em seguida, faz-se uma descrição do Exame de Proficiência aplicado para estrangeiros no Brasil (Exame Celpe-Bras). Por conseguinte, ocorrerá a análise do referido trabalho que consiste na descrição de provas do Exame Celpe-Bras nas três últimas edições. Tal análise compreenderá, especificamente, a terceira e a quarta tarefa da prova, que contemplam o processo de produção de texto. Essa análise consiste na averiguação de tais propostas com o intuito de observar se as questões presentes para a produção de um dado gênero textual são contempladas. Faremos uma análise isolada de cada uma das propostas de produção de texto e outra análise comparativa.

Para finalizar o presente artigo, traremos o fechamento das questões levantadas ao longo das seções, culminando nas considerações finais.

\section{Discutindo SOBRE GÊNEROS TEXTUAIS}

Inicialmente, aborda-se o tratamento dado às concepções da linguagem, tendo em vista a articulação entre tais concepções, o ensino de língua portuguesa e os textos utilizados nas aulas. Pode-se perceber que o modo de se conceber a língua influencia diretamente no processo de ensino-aprendizagem e também nos modelos que configuram as aulas de língua portuguesa. Os estudos que envolvem essa articulação tratam prioritariamente das aulas de português como língua materna, no entanto, ampliaremos tal articulação para as aulas de português como língua estrangeira.

\section{CONCEPÇÕES DE LiNGUAGEM}

Observa-se que as concepções de linguagem estão estritamente relacionadas ao contexto histórico, social, político e cultural da sociedade em que uma dada língua está inserida. Assim, evidencia-se que a configuração das concepções mudou no decorrer dos anos. De início, no Brasil Colonial, o ensino se pautava apenas no processo de alfabetização. Os estudos que se estendiam além da alfabetização eram voltados para o ensino da gramática normativa. A Reforma Pombalina instituiu o ensino da língua portuguesa obrigatório em Portugal e no Brasil, no entanto, tal ensino se voltou principalmente para os aspectos da gramática normativa. O estudo se pautava no reconhecimento das normas gramaticais e no estudo de antologias. Esse período foi marcado pela concepção de língua como sistema. Ensinar português consistia em reconhecer o sistema linguísti- 
co, aprender a gramática da língua e o uso de textos para através destes realizar análise gramatical. (SOARES, 1998, p.55) Essa concepção reflete o contexto sociopolítico da época, tendo em vista que as camadas mais privilegiadas tinham acesso e conheciam as normas gramaticais, consolidando o processo de segregação social ainda mais. A língua, nesta concepção, é tratada como estática e o conhecimento linguístico está presente na mente do usuário da língua. Pode-se asseverar aqui que a língua é um reflexo do pensamento. Koch (2002, p.16) trata da concepção de língua como representação do pensamento e a descreve.

$\mathrm{Na}$ concepção de língua como representação do pensamento e de sujeito como senhor absoluto de suas ações e de seu dizer, o texto é visto como produto - lógico - do pensamento (representação mental) do autor, nada mais cabendo ao leito/ ouvinte senão "captar" essa representação mental, juntamente com as intenções (psicológicas) do produtor, exercendo, pois, um papel essencialmente, passivo. (KOCH, 2002, p.16)

Posteriormente, o quadro linguístico se alterou, houve a concepção da linguagem que tratou da língua como instrumento de comunicação. A demanda da escola é voltada para as camadas populares e não mais para as camadas privilegiadas. Devido ao contexto histórico-social do Regime Militar, do avanço do Capitalismo e da Expansão Industrial, a proposta educacional foi a de atribuir à escola o papel de fornecer recursos humanos para a sociedade, assim, houve a qualificação para o trabalho. Os conteúdos de ensino ganharam sentido instrumental. As aulas de português eram intituladas de Comunicação e Expressão e ofereciam meios para desenvolver cada vez mais a comunicação em língua portuguesa. (SOARES, 1998) Os objetivos dessas aulas eram pragmáticos e utilitários, segundo os defensores desta concepção. Para Soares, trata-se de desenvolver as habilidades de expressão e compreensão de mensagens, que reflete no uso da língua. Nesse cenário sócio-histórico, o ensino da gramática normativa foi substituído pela teoria da comunicação.

A terceira concepção da linguagem trata da língua como interação. Aqui, o processo de interação ocorre entre autor, texto e leitor. Desse modo, altera-se o modo de compreender o ensino da leitura e da escrita. $\mathrm{O}$ aluno, nesta concepção, passou a ser considerado sujeito ativo que constrói suas habilidades e seus conhecimentos da linguagem oral e escrita em interação com os outros indivíduos e com a própria língua (SOARES, 1988, p. 59). Koch define as características desta concepção:

na concepção interacional (dialógica) da língua, na qual os sujeitos são vistos como atores/construtores sociais, o texto passa a ser considerado o próprio lugar da interação e os interlocutores, como sujeitos ativos que - dialogicamente - nele se constroem e são construídos. Desta forma há lugar, no texto, para toda uma gama de implícitos, dos mais variados tipos, somente detectáveis quando se tem, como pano de fundo, o contexto sociocognitivo dos participantes da interação (KOCH, 2002, p. 17).

Para realçar algumas das questões tratadas nesta seção, faz-se necessário mencionar que apesar dos estudos sobre gêneros textuais já se fazerem presentes desde Platão e Aristóteles, nas primeiras concepções de linguagem não se faziam menção explícita a gêneros textuais. A concepção de língua como sistema e a concepção de língua como instrumento de comunicação não apresentavam modelos linguísticos que contemplassem o estudo voltado para os gêneros textuais. $\mathrm{O}$ trabalho da primeira concepção tratava do texto como um suporte para questões da norma da língua 
portuguesa, já a segunda concepção abordava o texto com o propósito puramente comunicativo. A concepção que trata de teorias dos gêneros textuais de forma mais completa compete à língua como interação. Nesse contexto, a manifestação dos gêneros textuais se faz mais evidente, direcionando-a para as aulas de língua portuguesa.

A seguir, discutem-se algumas questões voltadas especificamente para os gêneros textuais e os propósitos sócio-discursivos de tais gêneros no ensino de português.

\section{GÊNEROS TEXTUAIS E ENSINO DE LÍNGUA}

De início, faz-se importante discutir a respeito dos gêneros textuais, além da utilização de tais gêneros nas aulas de língua portuguesa. $O$ trabalho voltado para os gêneros textuais já se apresentam nas aulas de língua portuguesa como língua materna há algum tempo. Os pontos que favorecem uma prática aplicada com os textos e suas características, além da própria estrutura dos textos, marcam as diretrizes para o processo de ensino-aprendizagem. Isso corrobora com a concepção de língua como interação social, tratada no sociointeracionismo (VYGOTSKY, 1978). Tal concepção de língua dialoga diretamente com a proposta dos gêneros textuais.

O uso da linguagem é o meio de apropriação das situações presentes nas esferas da sociedade. De acordo com Kleiman, "nossas atividades são realizadas no mundo social, em situações concretas, e é através da linguagem, nas suas diferentes modalidades, que realizamos muitas das ações que nos interessam” (KLEIMAN, 2003, p. 34). Desse modo, pode-se pensar que a língua não é tratada como algo estanque, executada como sistema de regras exercidas automaticamente. A língua como processo social se caracteriza como molde manipulado pelo uso linguístico do falante. A percepção do falante a respeito do uso se adequa aos diversos contextos de utilização dos textos orais e escritos. Dessa forma, o conhecimento da língua que o falante já possui é capaz de fazê-lo utilizar determinadas formas em detrimento de outras, além de reconhecer a composição dos variados textos que circundam o meio social. E isso é o que caracteriza uma teoria de gênero textual/discursivo (DELL'ISOLA, 2007; BAZERMAN, 2005; CRISTÓVÃO 2005; DIONÍSIO \& BEZERRA, 2005; MARCUSCHI, 2005; DOLZ e SCHNEUWLY, 2004).

Segundo Marcuschi, "para a noção de gênero textual, predominam os critérios de ação prática, circulação sócio-histórica, funcionalidade, conteúdo temático, estilo e composicionalidade" (MARCUSCHI, 2002, p. 24). Além do tipo de linguagem, da estrutura e da composição que fazem o falante associar um conjunto de informações a um dado gênero, o usuário da língua também é capaz de verificar de forma inconsciente a adequação do texto utilizado. Isso ocorre por que há um processo de apropriação do texto, fazendo com que gere uma adequação linguística na esfera social.

O uso dos textos nas esferas sociais é levado para o ensino de língua, tendo em vista que o ensino de língua portuguesa deve se configurar como produto de construções sociais. Não seria um objetivo apropriado para o ensino de língua portuguesa contemplar aspectos dissociados daquilo que permeia o cotidiano. $\mathrm{O}$ uso de textos de naturezas diversas se manifesta com frequência no meio social. O reflexo disso é a discussão que deve embasar o conteúdo presente em um artigo de opinião, por exemplo, além das marcas linguísticas e estruturais que caracterizam tal gênero como pertencente a uma categoria argumentativa. Além disso, tratar da percepção que o diferem de outros gêneros também argumentativos e de outras tipologias textuais. 
Para caracterizarmos ou configurarmos um determinado gênero devemos observar o lugar de seus dizeres. Além disso, há diferentes perspectivas para se caracterizar os gêneros textuais a partir das influências teóricas que alicerçam os estudos (BRONCKART, 1999; DOLZ \& SCHNEUWLY, 1998; MILLER, 1994; BAKHTIN, 1992; SWALES, 1990; HALLIDAY, 1978). "O que é gênero? [...] desenvolvemos a ideia metafórica do gênero como (mega-)instrumento para agir em situações de linguagem" (DOLZ \& SCHNEUWLY, 2004, p.12).

Em muitos casos, o gênero textual não é determinado por ele mesmo. É necessário observarmos o suporte que o gênero está inserido. Desse modo, pode-se perceber que um texto não é definido apenas pelo texto, entretanto, há elementos que circundam um dado gênero textual. Tais elementos colaboram na descrição e no entendimento linguístico do gênero: "em muitos casos são as formas que determinam o gênero e, em outros tantos serão as funções. Contudo, haverá casos em que será o próprio suporte ou o ambiente em que os textos aparecem que determinam o gênero presente (MARCUSCHI, 2002, p. 21).

Para além da discussão entre gênero textual e suporte, pode-se evidenciar ainda que o uso de determinado gênero é caracterizado a partir do contexto de produção, isto é, reconhecer os lugares sociais dos interlocutores se torna fundamental para determinar o entendimento de dado gênero textual. Dessa maneira, amplia-se o conhecimento que o sujeito possui para dimensionar a finalidade arraigada no texto. De acordo com Marcuschi (2002, p. 34), "não há só a questão da produção adequada do gênero, mas também um uso adequado".

Além da estrutura de um texto, os elementos linguísticos fornecem ferramentas que auxiliam na compreensão. A prática de análise linguística mantém relação direta com o texto. Não se pode fazer análise linguística com frases descontextualizadas. Se assim fosse, estar-se-ia recorrendo ao antigo processo de ensinar gramática normativa sem nenhuma base textual. O ensino deve partir de um texto. Esse texto precisa ser caracterizado como um dado gênero textual, escolhido previamente pelo professor, analisando questões composicionais, estruturais e de estilo. A partir disso, podem-se averiguar a presença de elementos linguístico-discursivos presente no texto. Cada gênero textual apresenta uma particularidade no que concerne aos elementos linguísticos explícitos. Por isso, a questão da seleção prévia dos gêneros que podem ser trabalhados em sala de aula se faz importante.

O sentido de um texto é, portanto, construído na interação texto-sujeitos (ou texto-co-enunciadores) e não algo que preexista a essa interação. Também a coerência deixa de ser vista como mera propriedade ou qualidade do texto, passando a dizer respeito ao modo como os elementos presentes na superfície textual, aliados a todos os elementos do contexto sociocognitivo mobilizados na interlocução, vêm a construir, em virtude de uma construção dos interlocutores, uma configuração veiculadora de sentidos $(\mathrm{KOCH}$, 2002, p. 17).

Assim, pode-se asseverar que a diversidade presente em um dado texto torna o processo de ensino-aprendizagem mais eficiente, já que se trabalha de forma ampla, mostrando os elementos do texto em sua totalidade. Uma abordagem com análise linguística permite o trabalho com a leitura, analisando os discursos explícitos e implícitos em um texto de opinião, além dos discursos diretos e indiretos em um texto de cunho narrativo, por exemplo. Essas análises de leitura ultrapassam a questão estrutural do texto, pois permitem evidenciar questões semântico-discursivas presentes 
nos itens linguísticos utilizados. Ao se trabalhar com um gênero textual que contenha características de um tipo textual injuntivo, pode-se abordar a presença dos tempos verbais, ampliando as questões para além daquelas puramente gramaticais, estruturais e de nomenclatura. A presença de verbos no imperativo, por exemplo, pode sugerir comandos de ordem. Dessa forma, podem-se observar outros textos que apresentem verbos de natureza distinta daqueles. Esses aspectos são alguns exemplos de possíveis formas de incluir atividades de análise linguística dentro de um dado texto, ampliando as análises realizadas dentro de um dado gênero textual.

O trabalho com a oralidade e com a produção textual também é incluído dentro de uma abordagem da análise linguística. Mostram-se, assim, elementos típicos de textos orais, diferenciando-os e comparando-os aqueles dos textos escritos. O trabalho com a produção textual de um dado gênero textual é a parte final desse processo. Desse modo, pode-se intensificar o conhecimento do aluno para que possa escrever com propriedade um texto da mesma natureza daquele analisado anteriormente, por exemplo.

A seguir, mostraremos algumas das questões relacionadas especificamente ao ensino dos gêneros textuais nas aulas de PLE. Também faremos uma discussão acerca do uso dos elementos linguísticos presentes nos textos, que auxiliam no processo de ensino-aprendizagem.

\section{Ensino de gêneros textuais nas aulas de PLE}

Em relação às aulas de língua portuguesa como segunda língua também se deveria adotar uma metodologia voltada para os gêneros textuais, ressalvadas as diferenças no processo de ensino-aprendizagem para um falante nativo do português e para um falante estrangeiro. $O$ processo de produção de textos orais e escritos se desenvolve com base nas esferas sociais e o reflexo disso também deve permear as aulas de português como segunda língua (TOSSATI, 2009; MORITZ, MATIELO \& DELLAGNELO, 2015; CAPUTO, 2018.).

Enfatizar os aspectos funcionais e contextuais dos Gêneros Textuais [...] não implica negligenciar aspectos formais, [...], na medida em que tais aspectos configuram recursos que os usuários de língua agenciam para construir sentidos e assim realizar o propósito do gênero (MARCUSCHI, 2005 apud MORITZ et al, 2015, p. 39).

Todos os aspectos que envolvem as teorias de gêneros textuais podem ser apresentados dentro das aulas de PLE. O uso de tais textos favorecerá o aprendiz de PLE para posterior aplicação dos conhecimentos linguísticos em provas, como o Celpe-Bras, por exemplo. O processo de ensino-aprendizagem das aulas de PLE compreendido através dos gêneros textuais permite disseminar os valores atribuídos aos mecanismos linguísticos de leitura, oralidade, análise linguística e produção de texto.

No Brasil, apesar do crescente número de publicações para atender ao público que deseja aprender a nossa língua, ainda são poucos os estudos sobre a abordagem de gêneros textuais nos materiais didáticos utilizados nas aulas de português para estrangeiros (TOSSATI, 2009 apud MORITZ et al, 2015, p. 40).

Os materiais didáticos utilizados para as aulas de PLE também são um importante ponto de apoio, tendo em vista a recorrência dos professores pelo auxílio de formas para complementar o planejamento realizado. Além disso, o aumento desses materiais didáticos podem ampliar o rol de 
pesquisas na área, favorecendo ainda mais o processo de ensino-aprendizagem. O ensino de atividades, que tenham os gêneros textuais como eixo integrador, no centro da proposta metodológica, é desempenhado com resultados satisfatórios.

O trabalho com GTs em aulas de língua estrangeira faz-se coerente com a proposta de estimular e encorajar o aluno na participação das atividades, além de ser um facilitador do processo de inserção do aprendiz na língua alvo (TOSSATI, 2009, p. 2).

Assim, pode-se pensar que o processo de ensino-aprendizagem em PLE faz parte de um conjunto de ações que tendem a oferecer o conhecimento propício da língua portuguesa. O aprendiz de PLE se apropria do universo dos textos, colocando-se a respeito de determinadas temáticas e explorando os aspectos linguísticos do texto. Desse modo, isso contribui para o aprendizado mais eficaz da língua portuguesa e o domínio relacionado ao uso dos gêneros sócio-discursivos presentes no meio social brasileiro.

A seguir, realiza-se uma breve descrição sobre o Exame Celpe-Bras, seguida da análise proposta para este artigo, que consiste no levantamento e na discussão relacionados à produção de texto da terceira e da quarta tarefa do referido Exame nos anos de 2019, 2018 e 2017.

\section{DESCRIÇÃO DO EXAME}

O Exame Celpe-Bras consiste em uma avaliação para medir o nível de proficiência de estrangeiros em língua portuguesa. O principal objetivo dos candidatos estrangeiros na execução do exame é o de conseguir o certificado de proficiência em língua portuguesa. Esse certificado do Celpe-Bras é o critério para inserção em cursos de graduação e também para candidatos validarem diplomas de origem estrangeira, por exemplo. Faz-se necessário salientar que tal certificado é o único meio oficial reconhecido pelo governo do Brasil. De acordo com o portal do INEP, o "Certificado de Proficiência em Língua Portuguesa para Estrangeiros (Celpe-Bras) é o exame brasileiro oficial para certificar proficiência em português como língua estrangeira". Em relação à aplicação, o exame acontece nos postos aplicadores do Brasil com uma ou duas edições anuais.

O nível de proficiência testado no exame é realizado por meio escrito e também oral. O exame é composto da seguinte forma: quatro atividades voltadas para o desenvolvimento da produção escrita e uma atividade voltada para o desenvolvimento da produção oral. De início, descreveremos como ocorrem as atividades escritas. A primeira tarefa do exame é baseada em vídeo. Pede-se que o candidato veja um vídeo, que serve como motivação para execução de uma produção escrita. A segunda tarefa é semelhante à primeira, no entanto, a motivação se baseia em um áudio. A terceira e a quarta tarefa se baseiam em textos trazidos no próprio exame. Vale salientar que a terceira e a quarta tarefa constituem o alvo de investigação deste trabalho.

Posteriormente, ainda, cabe mencionar acerca da parte oral do exame. Essa parte oral consiste em uma conversa face a face baseada em textos escritos. O entrevistador fornece alguns textos para o candidato, caracterizados como elementos provocadores. A partir da leitura de um dado elemento provocador, desenvolve-se uma conversa entre entrevistador e candidato. A ideia se trata de promover uma "provocação" que determine a conversa. O conteúdo tratado na interação é observado por uma terceira pessoa, que não participa da conversa, apenas observa. Toda interação realizada entre entrevistador e candidato é gravada para posterior análise e acontece em um total de 
vinte minutos. Os primeiros cinco minutos são destinados para uma conversa em sobre respostas que o candidato expõe ao realizar a inscrição. Os quinze minutos restantes são destinados à leitura e à discussão acerca de três elementos provocadores, cinco minutos para cada um deles.

A importância do exame se dá ao privilegiar dois eixos integradores da língua portuguesa. Um que se baseia na escrita formal da língua e outro que contempla aspectos da oralidade. De acordo com o manual do exame, os critérios observados durante a interação face a face são os seguintes: a competência interacional, a fluência, a pronúncia, a adequação gramatical, a adequação lexical e a compreensão.

\section{Propostas de produção escrita no Exame Celpe-Bras}

Para esta análise, observaremos as propostas de produção de texto referentes à terceira e à quarta atividades do Exame Celpe-Bras. Faremos uma verificação acerca da presença de elementos que remetam ao processo criativo dos gêneros textuais. Ressalta-se que as propostas de produção textual observadas serão sempre as terceiras e as quartas tarefas de cada uma das edições selecionadas, tendo em vista que tais tarefas trazem tanto a proposta do texto quanto a solicitação de realização do texto de forma escrita. Isso difere das primeiras e das segundas tarefas que trazem elementos como vídeos e áudios para posteriormente solicitar uma produção de texto. Tal análise ocorrerá em ordem decrescente, isto é, de início descreveremos as provas do corrente ano e, em seguida, aquelas realizadas no ano de 2018 e de 2017.

\section{Propostas de produção de Texto: ediçÃo 2019}

A terceira tarefa da edição em questão foi intitulada de Parblets. A descrição da tarefa é a seguinte: Você é o presidente da Associação de Comerciantes de uma cidade onde ainda não há parklets. Após ler a reportagem, decidiu sugerir que os associados invistam na instalação dessas estruturas. Escreva a eles uma carta, explicando o que são os parklets e justificando a importância do investimento.

Nesta tarefa, há uma reportagem a respeito dos Parblets. Os Parblets são explicados como espaços criados em lugares públicos pela iniciativa privada com o intuito de aumentar a interação entre as pessoas. Diz-se, ainda, conforme a reportagem, que esses espaços já existem em algumas das capitais do Brasil.

De acordo com a proposta de produção textual, pede-se que se escreva o texto dentro do gênero textual carta. Pela descrição da proposta, esse gênero estaria mais relacionado a uma carta de solicitação. $\mathrm{Na}$ descrição da proposta também há a presença de elementos que sugerem um caráter argumentativo ao texto. Esses elementos podem ser percebidos pela presença da inserção de uma sugestão aos associados a respeito do investimento em instalações para a estrutura dos parklets. Outro ponto que pode ser observado é que o candidato enquanto autor da carta deve escrevê-la como presidente da associação de comerciantes de uma cidade. Desse modo, pode-se perceber que o remetente da carta é posto como autoridade pertinente para o desenvolvimento do texto. O caráter argumentativo presente na proposta culmina na sugestão de explicações e justificativas acerca da importância do investimento.

O que diferencia a carta argumentativa das demais cartas é o compromisso que ela assume como convencimento do interlocutor, e o que diferencia de uma simples dissertação 
argumentativa é que esta é dirigida a um interlocutor universal, enquanto aquela é dirigida a um interlocutor previamente especificado (RIEMMA \& TOSCANO, 2016, p. 306).

Em relação à quarta da edição foi intitulada de Sofrimentos Inevitáveis. A descrição da tarefa é a seguinte: Após ler o artigo, você decidiu escrever uma carta para a autora com a finalidade de discutir a tese defendida por ela, apresentando a sua opinião sobre o ponto de vista de Rosely Sayão.

Para esta tarefa, também se pede que escreva uma carta. O objetivo da carta se diferencia daquele observado na terceira tarefa. Aqui, a base da carta deve se basear no artigo mostrado. $\mathrm{Na}$ carta solicitada para esta produção de texto, pede-se ainda que candidato discuta a respeito da temática tratada pela autora. Desse modo, também se pode relacionar essa sugestão de produção textual como pertencente a um posterior desenvolvimento de texto de natureza argumentativa. Isso pode ser evidenciado na proposta também quando se pede que o candidato evidencie seu ponto de vista sobre o assunto abordado no artigo. Em síntese, esse artigo trata de questões que envolvem pais e filho, além de trazer alguns dos sofrimentos sofridos por ambas as partes, consoante o texto. Esses sofrimentos são descritos no artigo como situações que pais tendem a dizer não para os filhos ou se sentem forçados a fazer isso, por exemplo.

\section{Propostas de produção de Texto: ediçÃo 2018}

Na edição do ano de 2018, a terceira tarefa foi intitulada de Guia de Rodas. Essa tarefa trouxe a seguinte proposta de produção textual: Imagine que você tem um filho com dificuldades de locomoção e que, recentemente, vocês passaram a utilizar o aplicativo para celular Guiaderodas. Escreva um e-mail para Bruno Mahfuz elogiando esse aplicativo e descrevendo os benefícios que ele tem trazido para a vida de seu filho.

Aqui, traz-se uma reportagem sobre um aplicativo criado por um cadeirante com o intuito de auxiliar outras pessoas a conhecerem melhor os espaços da sociedade, como restaurantes, cinemas, teatros enfim. A proposta é relacionada a um dado gênero textual, tendo em vista que se pede a construção de um e-mail. As diretrizes em relação ao conteúdo que deve ser inserido no e-mail tratam apenas da sugestão da descrição dos benefícios atribuídos ao aplicativo. Pela proposta, pode-se verificar que o assunto tratado na carta deve ser de caráter descritivo, já que o candidato enquanto autor do texto deve mencionar os aspectos positivos do aplicativo. Em relação à linguagem utilizada no e-mail, depende da interação e do nível de pessoalidade estabelecida entre os integrantes da troca de mensagens.

Para finalizar as questões presentes na terceira tarefa da proposta de produção textual, pode-se asseverar que o texto auxiliar Aplicativo Guiaderodas funciona como mapa da acessibilidade é uma ferramenta importante para o auxilio da inserção dos benefícios que podem ser inseridos no corpo do e-mail. Em relação ao gênero e-mail, pode-se dizer que se trata de uma modernização das antigas cartas. Trata-se de uma forma moderna de correspondência entre as pessoas. No e-mail, há a presença de vocativo, de corpo do texto e de fechamento.

Em relação à quarta tarefa, que foi intitulada de Gênero e Comida, pode-se observar que também foi elaborada para contemplar um gênero textual. A descrição da tarefa é a seguinte: Depois de ler o texto Gênero e Comida, você decidiu escrever uma carta ao leitor para o site A Escotilha, 
retomando a questão apresentada por Isadora Rupp. Em seu texto, exponha o seu ponto de vista sobre o assunto e sugira atitudes que possam provocar mudanças desse paradigma na sociedade.

Para esta produção textual, também se solicita um carta, dessa vez, o gênero textual é caracterizado como carta ao leitor. Nesse texto, a sugestão também é inserir questões de natureza argumentativa. Os elementos que mencionam essas questões se apresentam quando pede que o candidato enquanto autor do texto exponha seu ponto de vista sobre o texto, além de explicitar possíveis mudanças para a sociedade a partir da leitura do texto auxiliar. Esse texto auxiliar de autoria de Isadora Rupp trata de questões que envolvem a alimentação e as pressões sofridas por mulheres em relação à alimentação. Dessa forma, a tarefa proposta fornece pressupostos para que o candidato possa elaborar argumentos, realçando seu posicionamento, acerca da temática.

Em relação ao gênero textual carta ao leitor, pode-se observar a presença de elementos predominantemente argumentativos. De acordo com Riemma e Toscano (2016), o gênero abordado possui como características a presença da opinião do leitor sobre textos publicados em jornal ou revista, além da intenção que o autor possui sobre o tema, podendo se manifestar de forma favorável ou contrária, e ainda, a presença da linguagem dependerá do perfil do autor, tendo em vista que o padrão culto da língua é predominante em textos dessa natureza. Em relação à estrutura do gênero, pode-se observar que se assemelha a uma carta pessoal com a presença de vocativo e expressão de despedida. Observa-se ainda a marca de introdução, de desenvolvimento e de conclusão, configurando a argumentação ao autor.

\section{Propostas de produção de Texto: ediçÃo 2017}

No ano de 2017, o Exame Celpe-Bras contou com duas edições, uma realizada no primeiro semestre e outra realizada no segundo semestre.

A terceira tarefa da primeira edição foi intitulada de ONG Areia. A descrição da proposta de produção textual pode ser observada a seguir: Depois de ler a notícia sobre a ONG Areia, você decidiu escrever uma carta a empresas da região, solicitando apoio para a instituição. Em seu texto, apresente o fundador da ONG Areia, o trabalho que ele realiza e explique de que maneiras as empresas podem colaborar com esse trabalho voluntário.

Para esta proposta, também há a solicitação de escrita do gênero textual carta. Além disso, há a presença de elementos que remetem à carta argumentativa. Isso pode ser percebido quando pede que o candidato explique o modo que as empresas podem colaborar com o trabalho desenvolvido pela ONG Areia. A argumentação do texto é latente ao pedir que se solicite apoio de empresas. Dessa forma, as bases argumentativas do autor do texto deve se manifestar nesse momento mais claramente. Ao mesmo tempo, também há presença de elementos que remetem à descrição. Isso pode ser evidenciado quando se pede que apresente o fundador da ONG.

A quarta tarefa da primeira edição foi intitulada de Bibliotecas. Para esta tarefa, pede-se que se leia um artigo de opinião intitulado de Bibliotecas: metamorfose ou morte? Já a tarefa foi descrita do seguinte modo: Você leu o artigo de opinião abaixo apresentado, e resolveu escrever uma carta para a seção "Leitor", respondendo à pergunta "Bibliotecas: metamorfose ou morte?" Em seu texto, você deverá posicionar-se sobre o assunto, concordando ou discordando dos argumentos apresentados pelo autor. 
Pode-se observar que também se pede para produzir uma carta ao leitor. Trata-se também da produção de um texto com marcas argumentativas para enfatizar o posicionamento do autor do texto sobre o tema abordado no artigo de opinião. Em relação à estrutura e à linguagem do gênero carta argumentativa, já discutimos as questões concernentes a tal gênero na seção anterior.

Em relação à terceira tarefa da segunda edição do Exame, pode-se observar que foi intitulada como Serra da Capivara. A descrição da proposta de produção textual é a que se segue: Como voluntário do Parque Nacional da Serra da Capivara, você ficou responsável por escrever um texto de apresentação para uma campanha de arrecadação de fundos para essa instituição. Em seu texto, que estará disponível no site do Parque, apresente o histórico e os trabalhos ali desenvolvidos, mostrando a importância das doações para a manutenção desse patrimônio histórico mundial.

De acordo com os elementos linguísticos presentes na proposta acima, pode-se verificar que há sugestões para o planejamento e elaboração de um texto de caráter expositivo e descritivo. Trata-se de um texto de apresentação, que será veiculado no site do Parque. O intuito de tal texto é o de fomentar a discussão acerca do trabalho desenvolvido na Serra da Capivara para conseguir fundos para a instituição.

Para a quarta tarefa da segunda edição do Exame, pode-se verificar que recebeu o título de Alunos ricos deveriam pagar pela universidade pública? Já a proposta de produção textual consiste no seguinte: Depois de ler o artigo intitulado "Alunos mais ricos deveriam pagar pela universidade pública?”, você resolveu escrever uma carta para o painel de leitores da revista Época manifestando-se sobre a questão. Em sua carta, retome a discussão do artigo e argumente a favor do seu ponto de vista, comparando a realidade brasileira com a do seu país.

Aqui, verifica-se que também se pede a produção de uma carta. O texto deverá ser publicado na seção para o leitor em uma dada revista. Desse modo, pode-se caracterizar o gênero como carta ao leitor. Pode-se constatar que o candidato ao escrever a carta deve-se posicionar de forma crítica, já que na proposta é solicitada a manifestação em relação à questão abordada no artigo que acompanha tal proposta.

\section{CONSIDERAÇÕES FINAIS}

Para dirimir as questões finais desse trabalho, faz-se necessário retomar duas questões principais abordadas na análise do estudo em questão. A primeira dessas questões diz respeito se de fato as proposta de produção de texto da terceira e quarta tarefas do Exame Celpe-Bras designam textos voltados para um dado gênero textual. Por isso, também foi importante analisar o desenvolvimento das propostas ao longo dos três últimos anos, que correspondem às quatro últimas edições do referido Exame. A segunda dessas questões diz respeito especificamente aos gêneros abordados no prova.

Uma das conclusões evidenciadas é a de que as propostas, de fato, procuram contemplar os aspectos contidos nas teorias dos gêneros textuais. Essas propostas das tarefas do Exame contêm elementos que direcionam a execução de comandos formados por aspectos linguísticos da construção dos gêneros solicitados. Desse modo, pode-se afirmar que as propostas contemplam de forma satisfatória as motivações para a construção de um determinado gênero textual.

Em relação à segunda questão, pode-se constatar que a maioria das propostas contempla o gênero textual carta. Pode-se mencionar que em pelo menos uma das propostas presentes em cada 
uma das edições do Exame analisadas aqui há a o comando para escrita de uma carta. De forma mais específica, dentro dos diferentes tipos e modelos de cartas que existem na esfera social, as mais recorrentes nas propostas são a carta argumentativa e a carta ao leitor. Pode-se perceber, ainda, que nas referidas propostas nem sempre há a presença de forma explícita da nomeação do gênero textual abordado, todavia, pelo conjunto de características que se apresentam na construção é possível inferir a abordagem do texto.

Pode-se verificar também que devido à presença de tais gêneros textuais, os aspectos argumentativos são valorizados. Desse modo, o que se espera do candidato ao realizar o Exame Celpe-Bras é organizar de forma coerente o pensamento, argumentando favoravelmente ou contrariamente sobre determinado tema ou assunto. Outro aspecto interessante a ser observado é a do comando nas propostas acerca do seguimento da norma padrão culta da língua portuguesa. Isso é interessante, pois nota-se a importância também de atividades que contemplem o caráter formal da língua nas aulas de PLE. Assim, pode-se constatar a importância do trabalho, nas aulas de PLE, voltado para a prática com gêneros textuais.

\section{REFERÊNCIAS}

ALMEIDA FILHO, J. C. P. Ensinar uma nova língua para aquisição. In: Fundamentos de Abordagem e Formação no Ensino de PLE e de outras línguas. Campinas, SP: Pontes Editores, 2011.

ANTUNES, I. As funções do léxico na construção do texto. In: Língua, texto e ensino: outra escola possível. São Paulo: Parábola Editorial, 2009, p. 141-160.

BAKTHIN, M. Estética da criação verbal. 4. ed., São Paulo: Martins Fontes, 2003.

BAZERMAN, C. Gêneros, agência e escrita. In: HOFFNAGEL, J. C. e DIONÍSIO, A. P. São Paulo: Cortez, 2006.

BRONCKART, J. P. Atividade de linguagem, textos e discursos: por um interacionismo sócio-discursivo. São Paulo: EDUC, 2003.

DELL’ISOLA, R. L. P. Retextualização de gêneros escritos. Rio de Janeiro: Lucerna, 2007.

CAPUTO, C. O uso de gêneros textuais no ensino de PLE na educação à distância. In: Revista Digital dos Programas de Pós-Graduação do Departamento de Letras e Artes da UEFS. Feira de Santana, v. 19, n. 3, p. 159-168, 2018.

DOLZ, J. e SCHNEUWLY, B. Gêneros e progressão em expressão oral e escrita - elementos para reflexões sobre uma experiência suíça (francófona). In Gêneros Orais e escritos na escola. Campinas - SP: Mercado de Letras, 2004.

CRISTÓVÂO, V. L. L. Aprendendo a planificar o próprio trabalho: genros textuais na formação de professores de língua estrangeira. In: CRISTÓVÂO, V. L. L. e NASCIMENTO, E. L. Gêneros textuais: teoria e prática II. Palmas e União da Vitória: Kayagangue, 2005, p. 153-162.

GERALDI, J. W. Unidades básicas do ensino do português. In: O texto na Sala de Aula. 4. ed., São Paulo: Ática, 2007, p. 73-74.

GERALDI, J. W. No espaço do trabalho discursivo, alternativas. In: . Portos de Passagem. São Paulo: Martins Fontes, 2003, p. 189-217.

HALLIDAY, M. A. K. Language as Social Semiotic. London: Edward Arnold, 1978.

KLEIMAN, A. B. e ASSIS, J. A. Significados e ressignificações do letramento: desdobramentos de uma perspectiva sociocultural sobre a escrita. Campinas, SP: Mercado de Letras, 2016.

KOCH, I. G. V. Concepção de língua, sujeito, texto e sentido. In: Desvendando os segredos do texto. São Paulo: Cortez, 2002, p. 13-20.

Manual do Exame - Certificado de Proficiência em Língua Portuguesa para estrangeiros, 2019. 
MARCUSCHI, B. O que nos dizem o SAEB e o ENEM sobre o currículo de língua portuguesa para o ensino médio. In: BUNZEN, C. e MENDONÇA, M. Português no ensino médio e formação do professor. São Paulo: Parábola Editorial, 2006, p. 53-82.

MARCUSCHI, L. A. Gêneros Textuais: definição e funcionalidade. In: DIONISIO, A. P.; MACHADO, A. R. e BEZERRA, M. A. Gêneros Textuais e Ensino. Rio de Janeiro: Editora Lucerna, 2002, p. 19-36.

MILLER, C. Genre as social action. In: FREEMAN e MEDWAY. Genre and new rhetoric. London: Taylor \& Francis Ltd, 1984.

MORITZ, M. E. W.; MATIELO, R. e DELLAGNELO, A. K. Gêneros textuais e produção escrita em livros didáticos de Português para estrangeiros: uma análise do livro Muito Prazer - Fale o Português do Brasil. In: SILVEIRA, R. e EMMEL, I. Um retrato do português como segunda língua: ensino, aprendizagem e avaliação. Campinas - SP: Pontes Editora, 2015, p. 33-56.

POSSENTI, S. Gramática e Política. In: GERALDI, J. W. O Texto na Sala de Aula. 4. ed. São Paulo: Ática, 2007, p. 47-53.

POSSENTI, S. Ensinar língua ou ensinar gramática? In: Por que (não) ensinar gramática na escola. Campinas - SP: Mercado de Letras, 1998, p. 53-56.

SOARES, M. Concepções de linguagem e o ensino da Língua Portuguesa. In: BASTOS, N. B. Língua Portuguesa: História, Perspectivas, Ensino. São Paulo: Educ, 1998, p. 53-60.

SWALES, J. M. Genre analysis: English in academic and research settings. Cambridge: Cambridge University Press, 1990. TOSCANO, G e RIEMMA, R. Palavra Colhida: Redação e Texto. 2. ed., Brasília: HTC, 2015.

TOSSATI, N. M. Gêneros textuais em livros didáticos para ensino de português para estrangeiros: ocorrência e funcionalidade. Anais do SILEL, v. 1, Uberlândia: EDUFU, 2009. 